\title{
A Longitudinal Examination of the Psychoeducational, Neurocognitive, and Psychiatric Functioning in Children with 22q11.2 Deletion Syndrome
}

\author{
Stephen R. Hooper, Ph.D. ${ }^{\mathrm{a}, \mathrm{b}}$, Kathleen Curtiss, Ph.D. ${ }^{\mathrm{b}}$, Kelly Schoch, M.S. ${ }^{\mathrm{b}}$, Matcheri S. \\ Keshavan, M.D. ${ }^{c}$, Andrew Allen, PhD. ${ }^{d}$, and Vandana Shashi, M.D. ${ }^{b}$ \\ aDepartment of Psychiatry and The Carolina Institute for Developmental Disabilities, University of \\ North Carolina School of Medicine, CB\# 7255, Chapel Hill, NC, USA, 27599-7255. \\ bDepartment of Psychiatry, Duke University Medical School, GSRB1 Box 103857, 595 LaSalle \\ St., Durham, NC, USA, 27710 \\ 'Department of Psychiatry, Harvard Medical School, Commonwealth Research Center, 75 \\ Fenwood Rd, $5^{\text {th }}$ Floor, Boston, MA, USA, 02115 \\ dDepartment of Biostatistics, Duke University School of Medicine, 7057 North Pavilion, Durham, \\ NC, USA 27710
}

\section{Abstract}

The present study sought to examine the longitudinal psychoeducational, neurocognitive, and psychiatric outcomes of children and adolescents with chromosome 22q11.2 deletion syndrome (22q11DS), a population with a high incidence of major psychiatric illnesses appearing in late adolescence/early adulthood. Little is known of the developmental changes that occur in the early teen years, prior to the age of highest psychosis risk. Data were collected from 71 participants (42 subjects with 22q11DS and 29 control subjects) at Time 1 (T1) and Time 2 (T2), approximately 3.5 years later. The 22q11DS group was significantly lower functioning than controls on IQ, neurocognition, and academic achievement at both T1 and T2. Children with 22q11DS also showed significantly greater social-behavioral difficulties and psychiatric symptoms, and were more likely to meet criteria for psychiatric disorders at both time points. In evaluating change over time from T1 to T2, the 22q11DS group did not show significant changes in psychoeducational or psychiatric outcomes relative to the controls, however, lack of expected age-related gains in attention regulation were noted. Within the 22q11DS group, an increase in the Attenuated Prodrome for Schizophrenia (number of psychiatric symptoms) was noted from T1 to T2 and four children with 22q11DS met criteria for Psychosis for the first time. Predictors at T1 that uncovered psychopathology symptoms at T2 included full-scale IQ, externalizing symptoms, and problem social behaviors. Overall, younger adolescent and preadolescent children with 22q11DS in this study exhibited slowed growth in attention regulation, with an increase in subclinical symptoms of schizophrenia, suggestive of increasing impairments in domains that are relevant to the high risk of Schizophrenia. Early predictors of later psychopathology included both cognitive and behavioral abnormalities. These findings begin to elucidate the trajectory of changes in psychopathology in children with 22q11DS in the years leading up to the onset of major psychiatric illnesses.

\section{(C) 2012 Elsevier Ltd. All rights reserved.}

Publisher's Disclaimer: This is a PDF file of an unedited manuscript that has been accepted for publication. As a service to our customers we are providing this early version of the manuscript. The manuscript will undergo copyediting, typesetting, and review of the resulting proof before it is published in its final citable form. Please note that during the production process errors may be discovered which could affect the content, and all legal disclaimers that apply to the journal pertain. 


\section{Keywords}

22q11.2 Deletion Syndrome; Velocardiofacial Syndrome; DiGeorge Syndrome; Psychoeducational Functioning in 22q11DS; Neurocognitive functioning in 22q11DS; Psychiatric functioning in 22q11DS; Schizophrenia Genetics

\section{Introduction}

Chromosome 22q11.2 Deletion Syndrome (22q11DS), also known as Velocardiofacial syndrome (VCFS) or DiGeorge Syndrome, is the most common microdeletion syndrome in humans with an incidence of 1:2,000 to 1:4,000 (Devriendt, Fryns, Mortier, van Thienen, \& Keymolen, 1998; Shprintzen, 2000b, 2008; Wilson et al., 1994). In addition to multiple medical problems, individuals with 22q11DS experience a wide range of neurocognitive impairments and a high rate of major psychiatric disorders (Robin \& Shprintzen, 2005; Shprintzen, 2000a).

Intellectual functioning in children with 22q11DS varies from the borderline to mild intellectual disability range, along with deficits in sustained attention, executive function, and visual spatial functioning, with some reported similarities to a non-verbal learning disability (De Smedt et al., 2007; Jacobson et al., 2010; Lewandowski, Shashi, Berry, \& Kwapil, 2007; Moss et al., 1999; Schoch et al., 2012; Swillen et al., 1997; Woodin et al., 2001). Common psychiatric disorders in childhood include Attention-Deficit/Hyperactivity Disorder (ADHD) and anxiety disorders such as Specific Phobias and ObsessiveCompulsive Disorder (OCD; Antshel et al., 2007). In particular, children with 22q11DS evidence a poor repertoire of social skills and high rates of internalizing symptoms (KileyBrabeck \& Sobin, 2006; Shashi et al., 2011). In a prior study, we found that about $60 \%$ of children with 22q11DS met criteria for at least one psychiatric diagnosis, with the most frequent diagnoses including ADHD and various anxiety disorders (Lewandowski et al., 2007; Young, Shashi, Schoch, Kwapil, \& Hooper, 2011). In later adolescence or early adulthood, upwards of $25 \%$ develop major psychiatric illnesses such as Schizophrenia, Bipolar illness, and Major Depression (Baker \& Skuse, 2005; Murphy, Jones, \& Owen, 1999; Papolos et al., 1996; Pulver et al., 1994; Usiskin et al., 1999).

\subsection{Longitudinal Investigations of Neurocognitive and Psychiatric Functioning in Children with 22q11DS}

In one of the first longitudinal studies of individuals with 22q11DS, Gothelf et al. (2005) reported significant declines in verbal IQ and expressive language scores across two time points separated by approximately five years. Similar findings were identified in subsequent longitudinal examinations by Gothelf and colleagues with an association between changes in various cortical structures, verbal deterioration, and the appearance of severe psychopathology being highlighted (Gothelf et al., 2007; Green et al., 2009). Abnormal developmental trajectories of cortical thickness, with cortical loss during adolescence, has been documented both cross-sectionally and longitudinally, which may affect neurocognitive and psychiatric functioning over time (Schaer et al., 2009). Most recently, Kates and colleagues documented a relationship between changes in brain structure and the emergence of prodromal schizophrenia symptoms at two time points over a three year time period (Kates, Antshel, et al., 2011; Kates, Bansal, et al., 2011). Although the developmental trajectories of most brain structures were similar to their matched controls, volumetric decreases in temporal lobe gray matter and verbal IQ were especially related to positive prodromal psychotic symptoms in their preadolescent sample of children with 22q11DS. Green et al. (2009) noted the need for ongoing prospective longitudinal studies to continue 
to examine the nature of these changes. Since most of the above studies included children with 22q11DS that were older or included both children and adults and/or examined change over time mainly as related to schizophrenia symptoms, little is known about the longitudinal changes in neurocognition and other psychiatric diagnoses in early adolescence.

\subsection{The Present Study}

The primary purpose of the current study was to examine the longitudinal psychoeducational, neurocognitive, and psychiatric functioning of a well characterized group of children and young adolescents with 22q11DS. We had previously reported children with 22q11DS as having an IQ in the borderline range, with deficits in executive function, attention and verbal memory (Lewandowski et al., 2007; Shashi, Berry, \& Keshavan, 2009). Our first research objective in this study was to provide a more comprehensive description of the psychoeducational, neurocognitive and psychiatric findings of our sample at T1, and also provide the newest findings of our sample's performance 3.5 years later (T2). A second research question examined change over time for the 22q11DS group in comparison to age and gender matched healthy controls across the psychoeducational, neurocognitive, and psychiatric domains. Finally, a third research question examined specific $\mathrm{T} 1$ variables as potential predictors of the emergence of targeted psychopathology at $\mathrm{T} 2$, approximately 3.5 years post study entry.

\section{Methods}

\subsection{Participants}

Forty-two children with 22q11DS, ages 7.0-15.67 years $(M=10.05, S D=2.49)$, were recruited either at Duke University Medical Center (DUMC) or Wake Forest Baptist Medical Center. All subjects with 22q11DS had a molecularly confirmed deletion of the 22q11.2 region. Twenty-nine healthy control participants were recruited by advertisement in local pediatric practices, schools, and the research study website at DUMC. Control participants ranged in age from 7.92 to 14.33 years $(M=10.13, S D=1.74)$ and were excluded if they had a severe neurodevelopmental disorder (e.g., Autism), or a personal or family history (first-degree relative) of Psychosis, Bipolar Disorder, or Major Depression.

\subsection{Measures}

Participants were administered measures to ascertain intelligence (Wechsler Intelligence

Scale for Children-III/IV [WISC-III/IV] Verbal Comprehension, Perceptual Reasoning, Full Scale IQ; Wechsler, 1991, 2003), academic achievement in reading, mathematics, and spelling (Wechsler Individual Achievement Test-II/III [WIATII/III] Reading, Mathematics, Spelling; Wechsler, 2001, 2009), and a priori designated aspects of neurocognition including attention (Continuous Performance Test Identical Pairs d-Prime and AX d-Prime [CPT-IP/ AX]; Cornblatt, Risch, Faris, Friedman, \& Erlenmeyer-Kimling, 1988), verbal memory (California Verbal Learning Test for Children [CVLT-C] Total Score; Delis, Kramer, Kaplan, \& Ober, 1993), and the executive functions of perseveration, cognitive flexibility (Wisconsin Card Sorting Test [WCST] Perseveration Errors; Chase-Carmichael, Ris, Weber, \& Schefft, 1999), working memory (WISC-IV Working Memory Index; Wechsler, 2003), and processing speed (WISC-IV Processing Speed Index; Wechsler, 2003). Due to the high risk of schizophrenia in later life for children with 22q11DS, these measures were selected based on the recommendations of the Measurement and Treatment Research to Improve Cognition in Schizophrenia (MATRICS) task force, developed by the National Institute of Mental Health (NIMH). This task force identified seven domains of cognitive functioning and impairment that are central to schizophrenia, such as Speed of Processing, Attention/Vigilance, Working Memory, Verbal Learning, (Kern, Green, Nuechterlein, \& Deng, 2004). 
Psychiatric status was assessed by the presence of psychiatric diagnoses (Computerized Diagnostic Interview Schedule for Children, Version IV [DISC-IV]; Shaffer, Fisher, Lucas, Dulcan, \& Schwab-Stone, 2000), and social-behavioral functioning (Child Behavior Checklist Internalizing, Externalizing, and Total Problems summary scores; Achenbach \& Ruffle, 2000; Social Skills Rating System Total Score and Behavior Problems Score; Gresham \& Elliot, 1990), as reported by parents. Prodromal symptoms of schizophrenia were assessed using the Structured Interview for Prodromal Symptoms (SIPS; McGlashan et al., 2001) and Global Assessment of Functioning (GAF) with the Diagnostic and Statistical Manual of Mental Disorders GAF Scale ( $4^{\text {th }}$ ed., text rev.; DSM-IV-TR; American Psychiatric Association [APA], 2000), and socioeconomic status (SES) of participants' families was ascertained using the Hollingshead Two Factor Index of Social Position Scale (Hollingshead, 1957).

The initial neuropsychological and psychiatric evaluations were administered followed by a subsequent evaluation (T2) approximately 3.46 years ( $S D=0.93$ years) later in the 22q11DS group and 3.5 years $(S D=0.73$ years) later in the control group, $F(1,67)=.37, p=.54$. Evaluations were conducted by trained psychology graduate students and post-doctoral fellows in clinical psychology under the supervision of a licensed neuropsychologist. Those conducting the evaluations were not blinded to the intent of the study or group membership of the participant.

\subsection{Data Analyses}

Preliminary analyses examined group differences at T1 and T2 on sociodemographic variables to determine the need to control for any of these variables in subsequent analyses and to address the first research question. The two groups were compared across the psychoeducational, neurocognitive, and psychiatric variables using a multivariate analysis of variance (MANOVA), with follow-up univariate procedures to compare continuous variables and associated partial eta square $\left(\eta^{2} p\right)$ as a metric for effect sizes. Fisher's Exact Test (FET) and Chi-Square procedures were used for comparison of categorical variables. For group comparison on the neurocognitive variables, chronological age was included as a covariate given that the CPT-IP/AX variables were entered as raw scores and needed to be adjusted for age. To correct for error inflation due to multiple post-hoc comparisons, individual analyses of variance (ANOVA) were examined only if the overall MANOVA model was significant.

To address the second research question related to change over time, similar analytic strategies were employed, with a particular focus on the group $\mathrm{x}$ time point interaction. Additionally, to examine possible changes in the presence of specific psychiatric diagnoses and symptoms, we characterized change as a categorical variable (i.e., no change, loss of a diagnosis, gain of a diagnosis) for targeted diagnoses (i.e., Schizophrenia, ADHD, Any Anxiety Disorder, Specific Phobia, Major Depression) and for schizophrenia symptoms (no change, fewer, or more symptoms), and conducted Chi Square analyses to examine any differential change in diagnosis between the groups.

Finally, to address the third research question, a series of linear regression models were employed solely with the 22q11DS sample to identify specific predictors for symptoms of Specific Phobia, OCD, Major Depression, ADHD, and Schizophrenia. The regression models were constructed using preliminary correlations between the socioeconomic, psychoeducational, neurocognitive, and psychiatric variables at $\mathrm{T} 1$ and the number of symptoms for each disorder at T2. For all data analyses we used SPSS version 18.0. 


\section{Results}

\subsection{Sample Description}

3.1.1 Initial Evaluation at Time 1 (T1)—Data were collected from 71 participants at T1, of which 42 were diagnosed with 22q11DS and 29 were healthy controls. Initial neuropsychological results on a subset of these individuals have been previously reported elsewhere (Lewandowski et al., 2007). All 71 participants are part of a cohort of over 160 children with 22q11DS and control subjects who are part of a longitudinal study to ascertain the trajectory of neuropsychology in children with 22q11DS. In the current study, we report on $\mathrm{T} 1$ and $\mathrm{T} 2$ findings for only those participants on whom we have completed a T2 assessment. A one-way analysis of variance (ANOVA) indicated no differences at T1 between the two groups on age, $F(1,70)=0.02, p=.88$, or gender, FET $p=.48$, with $43 \%$ of the 22q11DS group and $51 \%$ of the control group being female. There was also no significant difference in SES between the two groups, $F(1,70)=2.5, p=.116$ (22q11DS $M=33.21, S D=14.56$; Control $M=27.86, S D=12.97$ ). Finally, no significant differences in ethnicity were noted between the 22q11DS and control groups, $X^{2}(2)=1.05, p=.591$, with $92 \%$ of the 22q11DS group and $86 \%$ of the control group being Caucasian. The remaining ethnic categories were Hispanic (22q11DS=3\%, Controls=7\%) and African-American $(22 \mathrm{q} 11 \mathrm{DS}=5 \%$, Controls $=7 \%)$.

3.1.2 Follow-Up Evaluation at Time 2 (T2)—At T2, there were no significant differences between the groups on age, $F(1,70)=.190, p=.66$, (22q11DS $M=13.59, S D=$ 2.47 years; Control $M=13.82, S D=1.74$ years), or SES, $F(1,68)=1.12, p=.293$, (22q11DS $M=31.36, S D=14.8$; Control $M=27.56, S D=14.1$ ).

\subsection{Research Question 1: Group Differences at Study Entry (T1) and Follow-up (T2)}

3.2.1 Psychoeducational Findings-Psychoeducational findings from $\mathrm{T} 1$ and $\mathrm{T} 2$ can be seen in Table 1. At study entry, a MANOVA indicated significant differences between the 22q11DS and control groups on three indices of the WISC-IV with follow-up univariate ANOVAs showing significant differences between the two groups on all indices. On each index, children with 22q11DS scored significantly lower than controls, with effect sizes being large in magnitude.

A similar pattern was found for academic achievement scores, with an overall MANOVA showing a significant group difference on the WIAT scores. Achievement effect sizes ranged from moderate (spelling) to large (reading and mathematics).

At the T2 evaluation, the groups continued to be significantly different on the three WISCIV indices with follow-up univariate procedures showing differences on all the indices. As with T1, participants with 22q11DS scored lower on all three indices than the controls, with effect sizes remaining large in magnitude. Likewise, the 22q11DS group scored significantly lower than controls on the achievement measures of the WIAT. Effect sizes remained the same as at T1, ranging from moderate (spelling) to large (reading and math).

3.2.2 Neurocognitive Findings-Table 1 contains the neurocognitive means and standard deviations for each group at $\mathrm{T} 1$ and $\mathrm{T} 2$. For T1, a multivariate analysis of covariance (MANCOVA), controlling for chronological age, indicated a significant overall difference between the two groups. Follow-up univariate procedures revealed significant group differences on measures of attention, verbal memory, and executive functions. Effect sizes for all of the findings were in the moderate to large range. 
Examination of the neurocognitive findings at $\mathrm{T} 2$ continued to show significant differences between the groups. Specific group differences continued to be found on the CPT AX dPrime, CVLT Total, WCST Perseverative Errors, WISC-IV Working Memory, and WISCIV Processing Speed. Effect sizes for each of these differences continued to fall within the large range.

3.2.3 Psychiatric Findings-Table 2 contains the psychiatric findings for each group at $\mathrm{T} 1$ and T2. At T1, a MANOVA for general social-behavioral functioning revealed significant group differences. Follow-up univariate procedures showed significant differences between the two groups on the CBCL Total Problems and Internalizing Problems scales, with the individuals in the 22q11DS group showing more behavior problems than controls. Significant differences were not found on the CBCL Externalizing Problems scale or either of the SSRS scales. Overall effect sizes on the social-behavioral measures ranged from small (SSRS Total Social Skills and Behavior Problems scores, CBCL Externalizing Problems) to moderate (CBCL Externalizing Problems and Internalizing Problems) to large (CBCL Total Problems).

A second group comparison examined specific symptoms of targeted psychiatric diagnoses as endorsed by parents on the CDISC. The MANOVA did not show a significant difference between the two groups at $\mathrm{T} 1$ on the number of symptoms endorsed across the targeted diagnoses. When the groups were compared on meeting full criteria for any of the targeted psychiatric diagnoses at $\mathrm{T} 1$ as defined on the CDISC, participants in the 22q11DS group were not significantly more likely to meet criteria, $X^{2}(1)=3.63, p=.057$. This result, however, just missed reaching significance, with $64.3 \%$ of the participants in the 22q11DS group meeting criteria for a psychiatric diagnosis versus $41.3 \%$ of controls. The latter percentage was inordinately high due to the allowance of healthy controls into the study with a diagnosis of ADHD. This allowance also, however, created a conservative group comparison on the presence of psychiatric disorders, thus making the group differences even more striking. Given a more representative control sample, it is likely that there would have been a significant difference between groups when looking at the presence of any psychiatric diagnosis. Looking at group differences on specific diagnoses, a significant difference did emerge when examining the presence of any anxiety disorder, $\mathrm{X}^{2}(1)=14.8, p$ $<.001$, with $45.2 \%$ of the 22q11DS group meeting criteria for an anxiety disorder versus only $13.5 \%$ of controls. This was specifically due to the diagnosis of Specific Phobia, which was more likely in the 22q11DS group, $\mathrm{X}^{2}(1)=13.13, p<.001$. There were no significant differences noted between the groups for the presence of ADHD, FET $p=.98$, since ADHD was not a rule-out condition for the control group. At T1, none of the 22q11DS or control subjects had a diagnosis of Psychosis or symptoms of a Schizophrenia Prodrome. The use of psychotropic medication may have had an impact on whether an individual met criteria for a specific psychiatric diagnosis; however, there were no overall differences between the groups with respect to prescribed psychotropic medication use, $\mathrm{X}^{2}(2)=0.04, p=.83$.

Psychiatric findings at T2 (Table 2) were similar to those obtained at T1, with continued significant differences between groups being noted. At this time point, however, children with 22q11DS exhibited significantly more in the way of social problem behaviors as reported on the SSRS. They were again rated as having higher overall CBCL Total Behavior problems and Internalizing Problems. Effect sizes again ranged from small (SSRS Total Social Skills, CBCL Externalizing Problems) to moderate (SSRS Behavior Problems, CBCL Internalizing Problems), to large (CBCL Total Problems). As with T1, parent ratings of overall social skills on the SSRS Total and CBCL Externalizing Problems were not significantly different between groups. 
With respect to group differences on the number of psychiatric symptoms reported by parents, an overall MANOVA was significant at T2, a different finding from T1. Children with 22q11DS were rated as having higher numbers of symptoms of Specific Phobia, Schizophrenia, OCD, ADHD, and Major Depression symptoms (Table1). Effect sizes were small for these group differences.

At T2, children in the 22q11DS group continued to be more likely to meet criteria for any DSM-IV-TR disorder overall, $\mathrm{X}^{2}(1)=6.01, p=.01$, any anxiety disorder overall, $\mathrm{X}^{2}(1)=$ 9.03, $p<.01$, and Specific Phobia, $X^{2}(1)=7.05, p<.01$. No differences were found in rates of diagnosis for any depression diagnosis, $\mathrm{X}^{2}(1)=2.17, p=.14$, ADHD, $\mathrm{X}^{2}(1)=2.1, p=.14$ or Schizophrenia, $X^{2}(1)=1.42, \mathrm{p}=.23$. When prodromal symptoms were examined, a higher rate of Attenuated Positive Prodromal symptoms was seen in the 22q11DS group, compared to the controls at $\mathrm{T} 2, \mathrm{X}^{2}(1)=3.94, \mathrm{p}=.047$. At $\mathrm{T} 1$, none of the subjects in either group had met criteria for the Attenuated Positive Prodromal Syndrome. As with T1, there were no group differences in prescriptions for psychotropic medication, $\mathrm{X}^{2-}(1)=2.4, p=.29$.

\subsection{Research Question 2: Changes in Psychoeducational, Neurocognitive, and Psychiatric Functioning Over Time}

To address the second research question, a series of MANOVAs were conducted to investigate potential differences in the developmental trajectory of the psychoeducational, neurocognitive, and psychiatric functioning of children with 22q11DS versus controls across the two time points. Here we were most interested in examining the group $\mathrm{x}$ time interaction across the variables so as to examine possible change over time on the various psychoeducational, neurocognitive, and psychiatric variables.

3.3.1 Changes in Psychoeducational Functioning-A MANOVA indicated that there was not a significant group $\mathrm{x}$ time point interaction for changes in cognition or academic achievement (Table 1) over time.

3.3.2 Changes in Neurocognitive Functioning-Within the neurocognitive domain, controlling for chronological age, a MANOVA indicated the presence of a trend towards a significant group $\mathrm{x}$ time point interaction (Table 1). Examining the follow-up univariate ANOVAs for the group $\mathrm{x}$ time point interaction revealed the groups to be significantly different on CPT IP d Prime, with the individuals in the 22q11DS group showing slower gains than those in the Control Group (Figure 1). There were no other group differences noted with respect to changes in neurocognitive functioning over time.

3.3.3 Changes in Psychiatric Functioning-For the general social-behavioral measures, the MANOVA produced a non-significant group $\mathrm{x}$ time point interaction (Table 2 ) and thus the individual ANOVAs were not examined. We then examined whether subjects in each group had a change in the number of total psychiatric symptoms from T1 to T2 (for Schizophrenia, OCD, Major Depression, Specific Phobia and ADHD) and found a significant group difference, with more children with 22q11DS exhibiting an increase in symptoms in each over time, relative to the control group, $t(53)=2.05, p<.05$.

When individual psychiatric diagnoses were examined from $\mathrm{T} 1$ to $\mathrm{T} 2$, there were no significant changes noted for either group on any anxiety disorders, $\mathrm{X}^{2}(2)=5.15, p=.07$; Specific Phobia, $\mathrm{X}^{2}(2)=4.55, p=.10$; Major Depression, $\mathrm{X}^{2}(1)=1.42, p=.23$; ADHD, $X^{2}(2)=2.42, p=.29$; or Schizophrenia $X^{2}(2)=2.7, p=.10$. Qualitatively, four subjects in the study had converted to Schizophrenia/Psychotic illness from T1 to T2. One diagnosed at the $\mathrm{T} 2$ assessment and the others diagnosed in the interim. Three of the four subjects were age 16 at the time of a diagnosis of a Psychotic Disorder and the fourth was 18 years of age. 
Three had a diagnosis of Schizophrenia and the fourth was a Psychotic Disorder, NOS. The three that had been diagnosed in the interim were all on antipsychotic medications at the time of $\mathrm{T} 2$ assessment and were in remission. We also examined change in the number of schizophrenia symptoms on the CDISC from $\mathrm{T} 1$ to $\mathrm{T} 2$ and found a significantly increased symptom count in children with 22q11DS over time, compared to control subjects, $t(43)=$ $2.0, \mathrm{p}<.05$.

We examined change in GAF scores from T1 to T2 in the 22q11DS versus control group and found that the control group made significantly more improvement in their GAF score over time compared to the 22q11DS group, $t(55)=-2.32, p<.05$, indicating poorer overall function with time in the 22q11DS group.

\subsection{Research Question 3: Predictors of Psychopathology}

To examine what specific sociodemographic, psychoeducational, neurocognitive, or psychiatric variables at T1 might be predictive of psychopathology at T2 in the 22q11DS group, we conducted preliminary correlations to identify specific variables for inclusion in a series of linear regressions. Variables that were significantly correlated with the number of symptoms for each disorder were included in each respective model. None of the variables were significantly correlated with Specific Phobia symptoms; consequently, a linear regression was not conducted for these symptoms. The results from the linear regression analyses can be seen in Table 3 .

For schizophrenia symptoms, there were six different variables that were significantly correlated: Full Scale IQ, $r(37)=-.44, p<.01$, Processing Speed, $r(36)=-.35, p<.05$, Working Memory, $r(35)=-.40, p<.05$, CBCL Total Problems, $r(35)=.42, p<.05$, CBCL Externalizing Problems $r(35)=.37, p<.05$, and SSRS Problem Behaviors, $r(35)=.36, p<$. 05 . When these variables were entered into the linear regression, lower Full Scale IQ at T1 was the only significant predictor of increased schizophrenia at T2 (Table 3).

For ADHD symptoms, there were three variables that were significantly correlated: CBCL Externalizing Problems, $r(35)=.48, p<.01$, CBCL Total Problems, $r(35)=.53, p=.001$, and SSRS Problem Behaviors, $r(35)=.55, p=.001$. The linear regression containing these variables as predictors found that only higher CBCL Externalizing Problems was predictive of higher ADHD symptoms (Table 3)

For OCD symptoms, there were five variables that were correlated. These included gender, with females having more OCD symptoms, $r(38)=.38, p<.05$, CBCL Total Problems, $r$ (35) $=.40, p<.05$, CBCL Externalizing Problems, $r(35)=.42, p<.05$, SSRS Total, $r(35)=-$. $43, p<.05$, and SSRS Problem Behaviors, $r(35)=.57, p<.001$. When the individual predictors were examined, female gender, higher CBCL Total Problem Behaviors and higher SSRS Problem Behaviors at T1 were significant predictors of higher OCD symptoms at $\mathrm{T} 2$.

Finally, for Major Depression symptoms, there were six variables that were significantly correlated: age, $r(38)=.35, p<.05$, Full Scale IQ, $r(37)=-.38, p<.05$, Processing Speed, $r$ $(36)=-.49, p<.01)$, CBCL Externalizing Problems, $r(35)=.45, p<.01$, CBCL Total Problems, $r(35)=.50, p<.01$, and SSRS Problem Behaviors, $r(35)=.41, p<.05$. Among the individual variables, Problem Social Behaviors was a significant predictor of Major Depression symptoms at $\mathrm{T} 2$. Increasing age also showed a trend to being a significant predictor $(\mathrm{p}=.05)$. 


\section{Discussion}

The primary objective of this study was to examine the longitudinal psychoeducational, neurocognitive and psychiatric outcomes in children and adolescents with 22q11DS at T1 and $\mathrm{T} 2$, with a specific focus on change over time. In addition, we were interested in capturing predictors of emergent psychopathology within our 22q11DS sample. This study is one of the largest, and the first to present a comprehensive longitudinal multifaceted assessment of cognition, behavior, and psychiatric findings over time in younger children and adolescents with 22q11DS, unlike previous studies that have largely focused on findings related to the schizophrenia risk. Our findings revealed the 22q11DS group to be significantly lower functioning than the controls in intellectual functioning, academic achievement, attention, verbal memory, cognitive flexibility, working memory, and processing speed at both $\mathrm{T} 1$ and $\mathrm{T} 2$. Children with 22q11DS also showed significantly more social-behavioral difficulties, psychiatric symptoms, and psychiatric disorders at both time points. These findings are similar to the available literature (Baker \& Skuse, 2005; De Smedt et al., 2007; Jacobson et al., 2010; Lewandowski et al., 2007; Murphy et al., 1999; Papolos et al., 1996; Pulver et al., 1994; Swillen et al., 1997; Woodin et al., 2001; Young et al., 2011) and we note that they persist over time. Thus, professionals working with this population need to be mindful that the psychoeducational, neurocognitive, social-behavioral and psychiatric difficulties do not improve over time.

The intellectual, academic achievement, and psychiatric outcomes targeted remained relatively stable over the interval studied. While other investigative teams have documented declines in overall intellectual functioning, verbal IQ, language abilities, and psychiatric status, such decline in cognition occurred in conjunction with the emergence of psychotic symptoms (Gothelf et al., 2007; Green et al., 2009; Kates, Antshel, et al., 2011). The lack of such deterioration in these specific functions in our sample may be related to the relatively younger age of our sample, as most of the children at $\mathrm{T} 2$ in our study have not yet entered the age range for the highest risk of major psychiatric illnesses (mean age in our study at T2 was 13.59 years, $S D=2.47$ ), and only a small number having converted to psychosis. In addition, our shorter follow-up time point of 3.5 years versus 5.0 years (Gothelf et al., 2007) may be a factor in not detecting significant changes in overall cognition and psychopathology. However, the presence of a time point in between preadolescent and late adolescence period, as provided in our study, should allow a more robust estimation of the trajectory of neuropsychological changes during the early adolescent period. We also obtained a relatively healthier cohort than in other studies. The majority of our cohort had been identified through a genetics clinic, wherein all children with 22q11DS are seen, rather than a specialty clinic such as a child psychiatry, neurodevelopmental, or cardiology clinic, where a biased sample could be available. , Due to this, our findings of stability in early adolescence may be more reflective of the state in a general community sample of children of 22q11DS. Finally, the lack of deterioration in our sample could be secondary to medication and other therapeutic and educational interventions being provided to the children in our sample. However, we have shown in prior studies that the children in our sample are not receiving all necessary treatments (Young et al., 2011), which lessens the validity of this argument.

Despite these differences, when we examined the number of total psychiatric symptoms and schizophrenia symptoms from T1 to T2 within the 22q11DS group, there was a significant increase, as well as an increase in the Attenuated Prodromal Syndrome in the 22q11 group, relative to controls, indicating that with time we could expect to see increasing number of psychoses as well. We also demonstrated that global functioning declines over time in children with 22q11DS, relative to controls. Furthermore, the 22q11DS group did show a significant and differential slowing of growth in their attention over time, suggesting a new 
finding in neurocognitive change in children with 22q11DS. These deficits undoubtedly will contribute to neurocognitive inefficiencies, and could be the precursors to later learning, adaptive, and psychiatric difficulties with advancing age and increased environmental challenges. These findings lead us to infer that during the early teen years, children with 22q11DS continue to experience a steady increase in psychiatric symptoms, despite no increases in categorical psychiatric diagnoses, as well as subtle changes in neurocognition and overall functioning. Vigilance with a goal of early detection and early intervention for psychopathology may be able to mitigate the progression of these concerning symptoms and signs, as these children move into the age of highest risk of major mental illnesses. Ours is the first study to highlight these early, yet important indicators.

Finally, consistent with earlier longitudinal studies (Johnstone, Ebmeier, Miller, Owens, \& Lawrie, 2005; Kim-Cohen et al., 2003), we were able to identify specific predictors of later psychopathology in our sample. For schizophrenia symptoms, lower Full Scale IQ at T1 was predictive of a larger number of schizophrenia symptoms at T2. A significant linear regression for Major Depression symptoms at T2 was observed, with problem social behaviors as a significant predictor and increasing age showing a trend. For Specific Phobia, none of our sociodemographic, neurocognitive, or social-behavioral variables at T1 were correlated with the number of symptoms at T2. For ADHD, CBCL Externalizing Problems was significantly predictive, a measure that typically is used to diagnose ADHD; and for OCD, female gender and having more behavior problems were predictive of symptoms at T2. Given the higher rate of psychopathology in our 22q11DS group as compared to healthy controls, we expect to see these variables surface as predictors as our sample ages into later adolescence and young adulthood (Johnstone et al., 2005; Kim-Cohen et al., 2003). It will be important for these predictive models to receive replication with other 22q11DS samples.

Although this study is one of the largest longitudinal studies examining neurodevelopmental and neuropsychiatric outcomes in children with 22q11DS, there are a few limitations. First, our sample size is small, and this may have contributed to our lack of findings related to change in categorical diagnoses over time as well as identifying specific predictors of emergent psychopathology. A second limitation is that we utilized parent ratings to determine the presence of social-behavioral difficulties, psychiatric symptoms, and specific psychiatric diagnoses, rather than interviewing the children. Although some may see our relatively shorter time between assessments as a limitation, we believe it a strength, providing a window into the trajectory of neurodevelopmental changes in early adolescence. It is also unclear how specific medications or other treatments may have affected the developmental trajectories of this sample. Although we did not see major changes over time, the impact of specific interventions may have had some effect on attenuating any early potential decline in function. Finally, the evaluators conducting the assessments in this study were not blinded to either the intent of the study or the diagnoses of the children being evaluated. This may have had an impact on more subjective ratings such as the GAF, which results showed were significantly different between healthy controls and the 22q11DS group.

This study provides important findings on the functioning of children and adolescents with 22q11DS, and serves to complement the few published longitudinal investigations. Our results showed a lower level of functioning at both time points accompanied by a heightened degree of psychiatric impairment. Over time, there are subclinical declines in cognition and increases in schizophrenia symptoms and prodromal signs, but in general, the presence of psychopathology appears to be relatively stable in the early years of adolescence. It will be critical for future studies to continue to examine the neuropsychiatric outcomes of children with 22q11DS, and for clinicians to engage in vigilant neurodevelopmental surveillance in later adolescence. 


\section{Acknowledgments}

This research was supported by funding from the National Institute of Mental Health (grant number R01MH78015-04) awarded to Vandana Shashi, M.D.

\section{References}

Achenbach TM, Ruffle TM. The Child Behavior Checklist and related forms for assessing behavioral/ emotional problems and competencies. Pediatric Reviews. 2000; 21(8):265-271.

Antshel KM, Faraone SV, Fremont W, Monuteaux MC, Kates WR, Doyle A, Biederman J. Comparing ADHD in velocardiofacial syndrome to idiopathic ADHD: a preliminary study. Journal of Attention Disorders. 2007; 11(1):64-73. [PubMed: 17606773]

Baker KD, Skuse DH. Adolescents and young adults with 22q11 deletion syndrome: psychopathology in an at-risk group. British Journal of Psychiatry. 2005; 186:115-120. [PubMed: 15684233]

Chase-Carmichael CA, Ris MD, Weber AM, Schefft BK. Neurologic validity of the Wisconsin Card Sorting Test with a pediatric population. The Clinical Neuropsychologist. 1999; 13(4):405-413. [PubMed: 10806452]

Cornblatt BA, Risch NJ, Faris G, Friedman D, Erlenmeyer-Kimling L. The Continuous Performance Test, identical pairs version (CPT-IP): I. New findings about sustained attention in normal families. Psychiatry Research. 1988; 26(2):223-238. [PubMed: 3237915]

De Smedt B, Devriendt K, Fryns JP, Vogels A, Gewillig M, Swillen A. Intellectual abilities in a large sample of children with Velo-Cardio-Facial Syndrome: an update. Journal of Intellectual Disability Research. 2007; 51(Pt 9):666-670. doi: 10.1111/j.1365-2788.2007.00955.x. [PubMed: 17845235]

Delis, DC.; Kramer, JH.; Kaplan, E.; Ober, BA. California Verbal Learning Test-Children's Version (CVLT-C). The Psychological Corporation; San Antonio, TX: 1993.

Devriendt K, Fryns JP, Mortier G, van Thienen MN, Keymolen K. The annual incidence of DiGeorge/ velocardiofacial syndrome. Journal of Medical Genetics. 1998; 35(9):789-790. [PubMed: 9733045]

Gothelf D, Eliez S, Thompson T, Hinard C, Penniman L, Feinstein C, Reiss AL. COMT genotype predicts longitudinal cognitive decline and psychosis in 22q11.2 deletion syndrome. Nature Neuroscience. 2005; 8(11):1500-1502.

Gothelf D, Feinstein C, Thompson T, Gu E, Penniman L, Van Stone E, Reiss AL. Risk factors for the emergence of psychotic disorders in adolescents with 22q11.2 deletion syndrome. American Journal of Psychiatry. 2007; 164(4):663-669. doi: 10.1176/appi.ajp.164.4.663. [PubMed: 17403981]

Green T, Gothelf D, Glaser B, Debbane M, Frisch A, Kotler M, Eliez S. Psychiatric disorders and intellectual functioning throughout development in velocardiofacial (22q11.2 deletion) syndrome. Journal of the American Academy of Child and Adolescent Psychiatry. 2009; 48(11):1060-1068. doi: 10.1097/CHI.0b013e3181b76683. [PubMed: 19797984]

Gresham, FM.; Elliot, SN. Social Skills Rating System. American Guidance Service, Inc; Circle Pines, MN: 1990.

Hollingshead, AB. Two factor index of social position. Hollingshead; New Haven: 1957.

Jacobson C, Shearer J, Habel A, Kane F, Tsakanikos E, Kravariti E. Core neuropsychological characteristics of children and adolescents with 22q11.2 deletion. Journal of Intellectual Disability Research. 2010; 54(8):701-713. doi: 10.1111/j.1365-2788.2010.01298.x. [PubMed: 20561146]

Johnstone EC, Ebmeier KP, Miller P, Owens DGC, Lawrie SM. Predicting schizophrenia: Findings from the Edinburgh High-Risk Study. The British Journal of Psychiatry. 2005; 186:18-25. doi: 10.1192/bjp.186.1.18. [PubMed: 15630119]

Kates WR, Antshel KM, Faraone SV, Fremont WP, Higgins AM, Shprintzen RJ, McCarthy C. Neuroanatomic predictors to prodromal psychosis in velocardiofacial syndrome (22q11.2 deletion syndrome): a longitudinal study. Biological Psychiatry. 2011; 69(10):945-952. doi: 10.1016/ j.biopsych.2010.10.027. [PubMed: 21195387]

Kates WR, Bansal R, Fremont W, Antshel KM, Hao X, Higgins AM, Peterson BS. Mapping cortical morphology in youth with velocardiofacial (22q11.2 deletion) syndrome. Journal of the American 
Academy of Child and Adolescent Psychiatry. 2011; 50(3):272-282. e272. doi: 10.1016/j.jaac. 2010.12.002. [PubMed: 21334567]

Kern RS, Green MF, Nuechterlein KH, Deng BH. NIMH-MATRICS survey on assessment of neurocognition in schizophrenia. Schizophrenia Research. 2004; 72(1):11-19. [PubMed: 15531403]

Kiley-Brabeck K, Sobin C. Social skills and executive function deficits in children with the 22q11 Deletion Syndrome. Applied Neuropsychology. 2006; 13(4):258-268. doi: 10.1207/ s15324826an1304_7 [doi]. [PubMed: 17362146]

Kim-Cohen J, Caspi A, Moffitt TE, Harrington H, Milne BJ, Poulton R. Prior juvenile diagnoses in adults with mental disorder: developmental follow-back of a prospective-longitudinal cohort. Archives of General Psychiatry. 2003; 60(7):709-717. [PubMed: 12860775]

Lewandowski KE, Shashi V, Berry PM, Kwapil TR. Schizophrenic-like neurocognitive deficits in children and adolescents with 22q11 deletion syndrome. American Journal of Medical Genetics Part B: Neuropsychiatric Genetics. 2007; 144(1):27-36.

McGlashan, TH.; Miller, TJ.; Woods, SW.; Rosen, JL.; Hoffman, RE.; Davidson, L.; Clinic, PR. Structured Interview for Prodromal Syndromes. Yale School of Medicine; New Haven, CT: 2001.

Moss EM, Batshaw ML, Solot CB, Gerdes M, Donald-McGinn DM, Driscoll DA, Wang PP. Psychoeducational profile of the 22q11.2 microdeletion: A complex pattern. Journal of Pediatrics. 1999; 134(2):193-198. [PubMed: 9931529]

Murphy KC, Jones LA, Owen MJ. High rates of schizophrenia in adults with velo-cardio-facial syndrome. Archives of General Psychiatry. 1999; 56(10):940-945. [PubMed: 10530637]

Papolos DF, Faedda GL, Veit S, Goldberg R, Morrow B, Kucherlapati R, Shprintzen RJ. Bipolar spectrum disorders in patients diagnosed with velo-cardio-facial syndrome: does a hemizygous deletion of chromosome 22q11 result in bipolar affective disorder? American Journal of Psychiatry. 1996; 153(12):1541-1547. [PubMed: 8942449]

Pulver AE, Nestadt G, Goldberg R, Shprintzen RJ, Lamacz M, Wolyniec PS, Housman D. Psychotic illness in patients diagnosed with velo-cardio-facial syndrome and their relatives. Journal of Nervous and Mental Disease. 1994; 182(8):476-478. [PubMed: 8040660]

Robin NH, Shprintzen RJ. Defining the clinical spectrum of deletion 22q11.2. Journal of Pediatrics. 2005; 147(1):90-96. doi: 10.1016/j.jpeds.2005.03.007. [PubMed: 16027702]

Schaer M, Debbane M, Bach Cuadra M, Ottet MC, Glaser B, Thiran JP, Eliez S. Deviant trajectories of cortical maturation in 22q11.2 deletion syndrome (22q11DS): A cross-sectional and longitudinal study. Schizophrenia Research. 2009 doi: 10.1016/j.schres.2009.09.016.

Schoch K, Harrell W, Hooper SR, Ip EH, Saldana S, Kwapil TR, Shashi V. Applicability of the Nonverbal Learning Disability Paradigm for Children With 22q11.2 Deletion Syndrome. Journal of Learning Disabilities. 2012 doi: 10.1177/0022219412443556.

Shaffer D, Fisher P, Lucas CP, Dulcan MK, Schwab-Stone ME. NIMH Diagnostic Interview Schedule for Children Version IV (NIMH DISC-IV): Description, differences from previous versions, and reliability of some common diagnoses. Journal of the American Academy of Child \& Adolescent Psychiatry. 2000; 39(1):28-38. doi: 10.1097/00004583-200001000-00014. [PubMed: 10638065]

Shashi V, Berry MN, Keshavan MS. Mechanistic approach to understanding psychosis risk in velocardiofacial syndrome. Current Pediatric Reviews. 2009; 5(2):89-104.

Shashi V, Veerapandiyan A, Schoch K, Kwapil T, Keshavan M, Ip E, Hooper S. Social skills and associated psychopathology in children with chromosome 22q11.2 deletion syndrome: implications for interventions. Journal of Intellectual Disability Research. 2011 doi: 10.1111/j. 1365-2788.2011.01477.x.

Shprintzen RJ. Velo-cardio-facial syndrome: a distinctive behavioral phenotype. Ment Retard Dev Disabil Res Rev. 2000a; 6(2):142-147. doi: 10.1002/1098-2779(2000)6:2<142::aid-mrdd9>3.0.co; 2-h. [PubMed: 10899808]

Shprintzen RJ. Velocardiofacial syndrome. Otolaryngologic Clinics of North America. 2000b; 33(6): 1217-1240. vi. [PubMed: 11449784]

Shprintzen RJ. Velo-cardio-facial syndrome: 30 Years of study. Developmental Disabilities Research Reviews. 2008; 14(1):3-10. doi: 10.1002/ddrr.2 [doi]. [PubMed: 18636631] 
Swillen A, Devriendt K, Legius E, Eyskens B, Dumoulin M, Gewillig M, Fryns JP. Intelligence and psychosocial adjustment in velocardiofacial syndrome: a study of 37 children and adolescents with VCFS. Journal of Medical Genetics. 1997; 34(6):453-458. [PubMed: 9192263]

Usiskin SI, Nicolson R, Krasnewich DM, Yan W, Lenane M, Wudarsky M, Rapoport JL. Velocardiofacial syndrome in childhood-onset schizophrenia. Journal of the American Academy of Child \& Adolescent Psychiatry. 1999; 38(12):1536-1543. [PubMed: 10596254]

Wechsler, D. Wechsler Intelligence Scale for Children. 3rd Edition. Psychological Corporation; New York: 1991.

Wechsler, D. Individual Achievement Test-II (WIAT-II). The Psychological Corporation; San Antonio, TX: 2001.

Wechsler, D. Intelligence Scale for Children. 4th Edition. The Psychological Corporation; San Antonio, TX: 2003.

Wechsler, D. Individual Achievement Test-III (WIAT-III). The Psychological Corporation; San Antonio, Texas: 2009.

Wilson DI, Cross JE, Wren C, Scramble P, Burn, Goodship J. Minimum prevalence of chromosome 22q11 deletion. American Journal of Human Genetics. 1994; 55:A169.

Woodin M, Wang PP, Aleman D, Donald-McGinn D, Zackai E, Moss E. Neuropsychological profile of children and adolescents with the 22q11.2 microdeletion. Genetics in Medicine. 2001; 3(1):34 39. [PubMed: 11339375]

Young AS, Shashi V, Schoch K, Kwapil T, Hooper SR. Discordance in Diagnoses and Treatment of Psychiatric Disorders in Children and Adolescents with 22q11.2 Deletion Syndrome. Asian Journal of Psychiatry. 2011; 4(2):119-124. doi: 10.1016/j.ajp.2011.03.002. [PubMed: 21743818] 


\section{Highlights}

Children with 22q11DS and controls underwent two neurocognitive and psychiatric evaluations 3.5 years apart.

Significant cognitive deficits and higher incidence of psychiatric manifestations seen in 22q11DS children relative to controls at both $\mathrm{T} 1$ and T2.

Slowed growth in attention, increased psychiatric symptoms and prodromal signs, and decreased GAF over time noted in 22q11DS children.

T1 predictors of psychopathology at T2 included full-scale IQ and social-behavioral problems. 


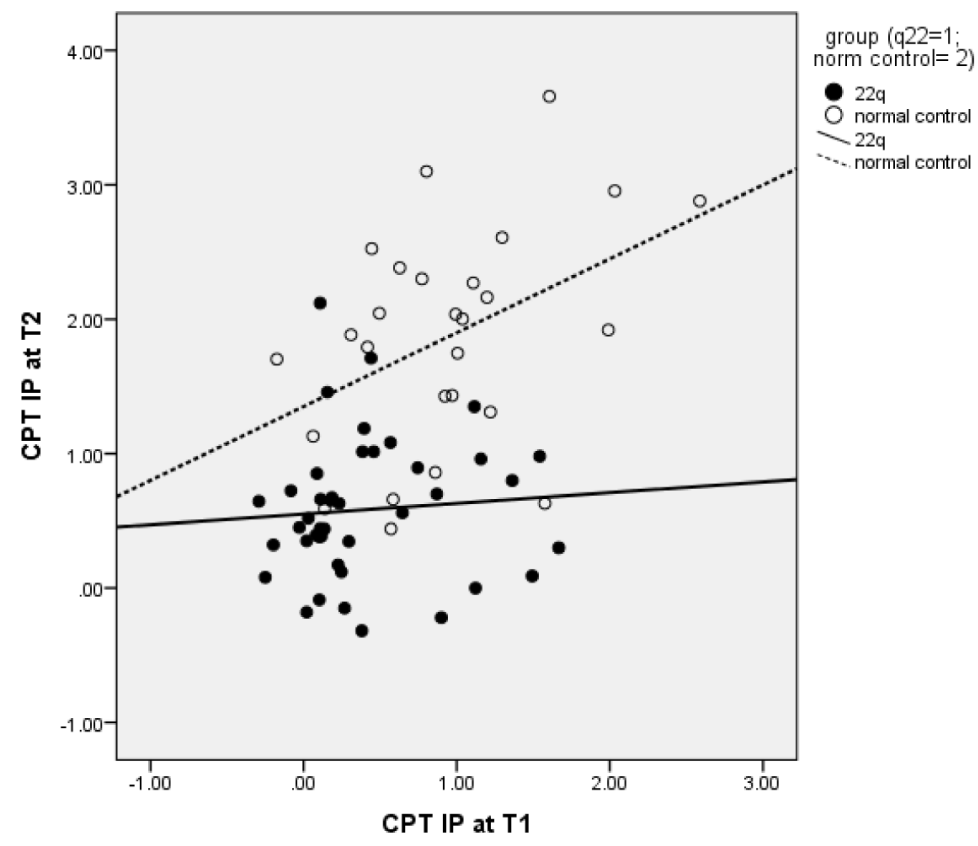

Fig. 1.

Scatterplot of Sustained Attention Scores at T1 and T2 in the 22q11DS group, relative to the Control group, demonstrating that there is a lack of an increase in CPT scores with age in the 22q11DS group, compared to the Control group 
Table 1

Group Comparisons at Time 1, Time 2, and Group x Time Interactions for Psychoeducational and Neurocognitive Functioning

\begin{tabular}{|c|c|c|c|c|c|c|c|c|c|}
\hline \multirow{3}{*}{$\begin{array}{l}\text { Psychoeducational } \\
\text { and } \\
\text { Neurocognitive } \\
\text { Measures }\end{array}$} & \multicolumn{8}{|c|}{ Evaluation Time Point } & \multirow{3}{*}{$\begin{array}{c}\text { Group X Time } \\
\text { Point } \\
\text { Interaction/Follow- } \\
\text { up Univariate F- } \\
\text { Values }\end{array}$} \\
\hline & \multicolumn{4}{|c|}{ Time Point 1} & \multicolumn{4}{|c|}{ Time Point 2} & \\
\hline & $\begin{array}{l}\text { 22q11DS } \\
\text { Group } \\
(n=41)\end{array}$ & $\begin{array}{c}\text { Control } \\
\text { Group } \\
(n= \\
28)\end{array}$ & F-Value & $\begin{array}{c}\text { Eta } \\
\text { Squared }\end{array}$ & $\begin{array}{l}\text { Group } \\
(n=41)\end{array}$ & $\begin{array}{c}\text { Control } \\
\text { Group } \\
(n= \\
29)\end{array}$ & F-Value & $\begin{array}{c}\text { Eta } \\
\text { Squared }\end{array}$ & \\
\hline $\begin{array}{l}\text { Psychoeducational } \\
\text { (IQ) }\end{array}$ & \multicolumn{4}{|c|}{$F(3,65)=43.09, p<.000$} & \multicolumn{4}{|c|}{$F(3,66)=42.46, p<.000$} & $\begin{array}{c}\mathrm{F}(3,132)=0.043 \\
p=.98\end{array}$ \\
\hline $\begin{array}{l}\text { WISC-IV Verbal } \\
\text { Comp. }\end{array}$ & $\begin{array}{c}77.54 \\
(11.08)\end{array}$ & $\begin{array}{l}104.82 \\
(13.13)\end{array}$ & $81.11^{* * * *}$ & .548 & $\begin{array}{l}75.68 \\
(11.15)\end{array}$ & $\begin{array}{l}104.28 \\
(10.36)\end{array}$ & $118.32^{* * *}$ & .635 & --- \\
\hline $\begin{array}{l}\text { WISC-IV } \\
\text { Perceptual } \\
\text { Reason. }\end{array}$ & $\begin{array}{c}77.07 \\
(12.67)\end{array}$ & $\begin{array}{l}106.29 \\
(12.97)\end{array}$ & $99.04^{* * * *}$ & .596 & $\begin{array}{c}77.98 \\
(13.99)\end{array}$ & $\begin{array}{l}105.97 \\
(12.25)\end{array}$ & $75.19^{* * *}$ & .525 & --- \\
\hline $\begin{array}{l}\text { WISC-IV Full } \\
\text { Scale IQ }\end{array}$ & $\begin{array}{l}73.29 \\
(11.85)\end{array}$ & $\begin{array}{l}105.86 \\
(11.37)\end{array}$ & $129.6^{* * * *}$ & .659 & $\begin{array}{c}72.22 \\
(13.15)\end{array}$ & $\begin{array}{l}105.48 \\
(10.36)\end{array}$ & $119.18^{* * *}$ & .637 & --- \\
\hline $\begin{array}{l}\text { Psychoeducational } \\
\text { (Achievement) }\end{array}$ & \multicolumn{4}{|c|}{$F(3,66)=18.99, p<.000$} & \multicolumn{4}{|c|}{$F(3,65)=19.32, p<.000$} & $\begin{array}{c}F(3,132)=0.346 \\
p=.79\end{array}$ \\
\hline Broad Reading & $\begin{array}{c}84.29 \\
(15.68)\end{array}$ & $\begin{array}{l}100.76 \\
(15.29)\end{array}$ & $19.1^{* * * *}$ & .219 & $\begin{array}{c}80.83 \\
(12.83)\end{array}$ & $\begin{array}{c}98.07 \\
(12.74)\end{array}$ & $30.52^{* * *}$ & .313 & --- \\
\hline $\begin{array}{l}\text { Broad } \\
\text { Mathematics }\end{array}$ & $\begin{array}{c}76.68 \\
(18.83)\end{array}$ & $\begin{array}{c}106.9 \\
(13.62)\end{array}$ & $54.37^{* * * *}$ & .444 & $\begin{array}{c}74.42 \\
(17.59)\end{array}$ & $\begin{array}{c}104.1 \\
(14.77)\end{array}$ & $54.52^{* * *}$ & .449 & --- \\
\hline Spelling & $\begin{array}{c}85.49 \\
(14.06)\end{array}$ & $\begin{array}{l}98.17 \\
(11.66)\end{array}$ & $15.84^{* * * *}$ & .189 & $\begin{array}{c}84.17 \\
(14.08)\end{array}$ & $\begin{array}{c}95.59 \\
(14.36)\end{array}$ & $10.85^{* *}$ & .139 & --- \\
\hline Neurocognitive & \multicolumn{4}{|c|}{$F(5,57)=58.00, p<.000$} & \multicolumn{4}{|c|}{$F(5,58)=58.00, p<.000$} & $\begin{array}{c}F(5,120)=1.80 \\
p=.11\end{array}$ \\
\hline CPT-IP d-Prime & $\begin{array}{c}0.41 \\
(0.52)\end{array}$ & $\begin{array}{c}0.94 \\
(0.64)\end{array}$ & $18.34^{* *}$ & .179 & $\begin{array}{l}0.58 \\
(.52)\end{array}$ & $\begin{array}{l}1.84 \\
(.80)\end{array}$ & $55.00^{* * *}$ & .476 & $\begin{array}{c}F=(1,120)=6.06 \\
p=.01\end{array}$ \\
\hline CVLT Total & $\begin{array}{l}38.78 \\
(10.61)\end{array}$ & $\begin{array}{l}53.84 \\
(9.86)\end{array}$ & $32.85^{* * * *}$ & .346 & $\begin{array}{l}35.66 \\
(11.35)\end{array}$ & $\begin{array}{l}51.37 \\
(8.56)\end{array}$ & $40.78^{* * *}$ & .373 & --- \\
\hline $\begin{array}{l}\text { WCST } \\
\text { Perseverative } \\
\text { Errors }\end{array}$ & $\begin{array}{l}87.58 \\
(8.80)\end{array}$ & $\begin{array}{l}104.81 \\
(14.00)\end{array}$ & $36.54^{* * * *}$ & .371 & $\begin{array}{c}88.97 \\
(14.17)\end{array}$ & $\begin{array}{l}110.44 \\
(18.24)\end{array}$ & $27.51^{* * *}$ & .317 & --- \\
\hline $\begin{array}{l}\text { WISC-IV } \\
\text { Working Memory }\end{array}$ & $\begin{array}{c}80.47 \\
(13.83)\end{array}$ & $\begin{array}{l}103.65 \\
(12.60)\end{array}$ & $46.51^{* * *}$ & .429 & $\begin{array}{c}82.08 \\
(17.11)\end{array}$ & $\begin{array}{l}105.33 \\
(14.13)\end{array}$ & $35.15^{* * *}$ & .347 & --- \\
\hline $\begin{array}{l}\text { WISC-IV } \\
\text { Processing Speed }\end{array}$ & $\begin{array}{c}79.79 \\
(15.17)\end{array}$ & $\begin{array}{l}102.58 \\
(13.65)\end{array}$ & $37.73^{* * * *}$ & .378 & $\begin{array}{c}72.92 \\
(12.66)\end{array}$ & $\begin{array}{c}99.48 \\
(12.73)\end{array}$ & $72.73^{* * *}$ & .511 & \\
\hline \multicolumn{10}{|l|}{$*$ Note. $p<0.05$} \\
\hline \multicolumn{10}{|l|}{$* * 0<0.01$} \\
\hline${ }^{* * *} p<0.001$ & & & & & & & & & \\
\hline
\end{tabular}

CPT-AX - Continuous Performance Test-AX Version; CPT-IP = Continuous Performance Test-Identical Pairs Version; CVLT = California Verbal Learning Test; WCST = Wisconsin Card Sorting Test; WISC-IV = Wechsler Intelligence Scale for Children, Fourth Edition. The MANCOVA for the neurocognitive measures used age as a covariate, since the CPT scores measures were entered as raw scores 
Table 2

Group Comparisons at Time 1, Time 2, and Group x Time Interactions for Psychiatric Functioning.

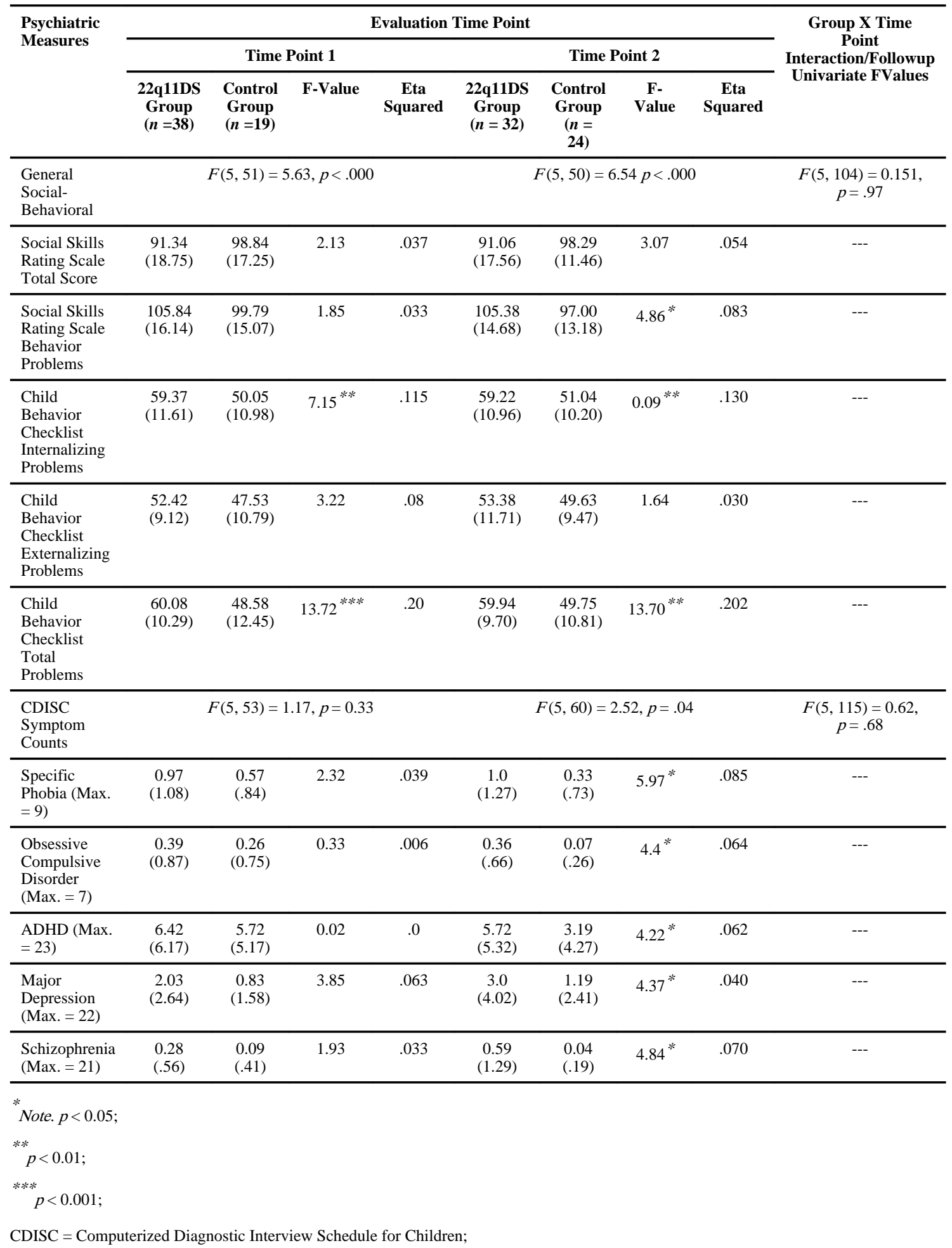


ADHD = Attention Deficit-Hyperactivity Disorde 
